\title{
Thermal evolution and phase transitions in electrochemically activated $\mathrm{Sc}_{2}\left(\mathrm{MoO}_{4}\right)_{3}$
}

Junnan Liua ${ }^{*}$, Neeraj Sharma ${ }^{a}$

a School of Chemistry, UNSW Sydney, Sydney NSW 2052, Australia

Corresponding author: J. Liu, Junnan.liu@unsw.edu.au

Supporting Information 


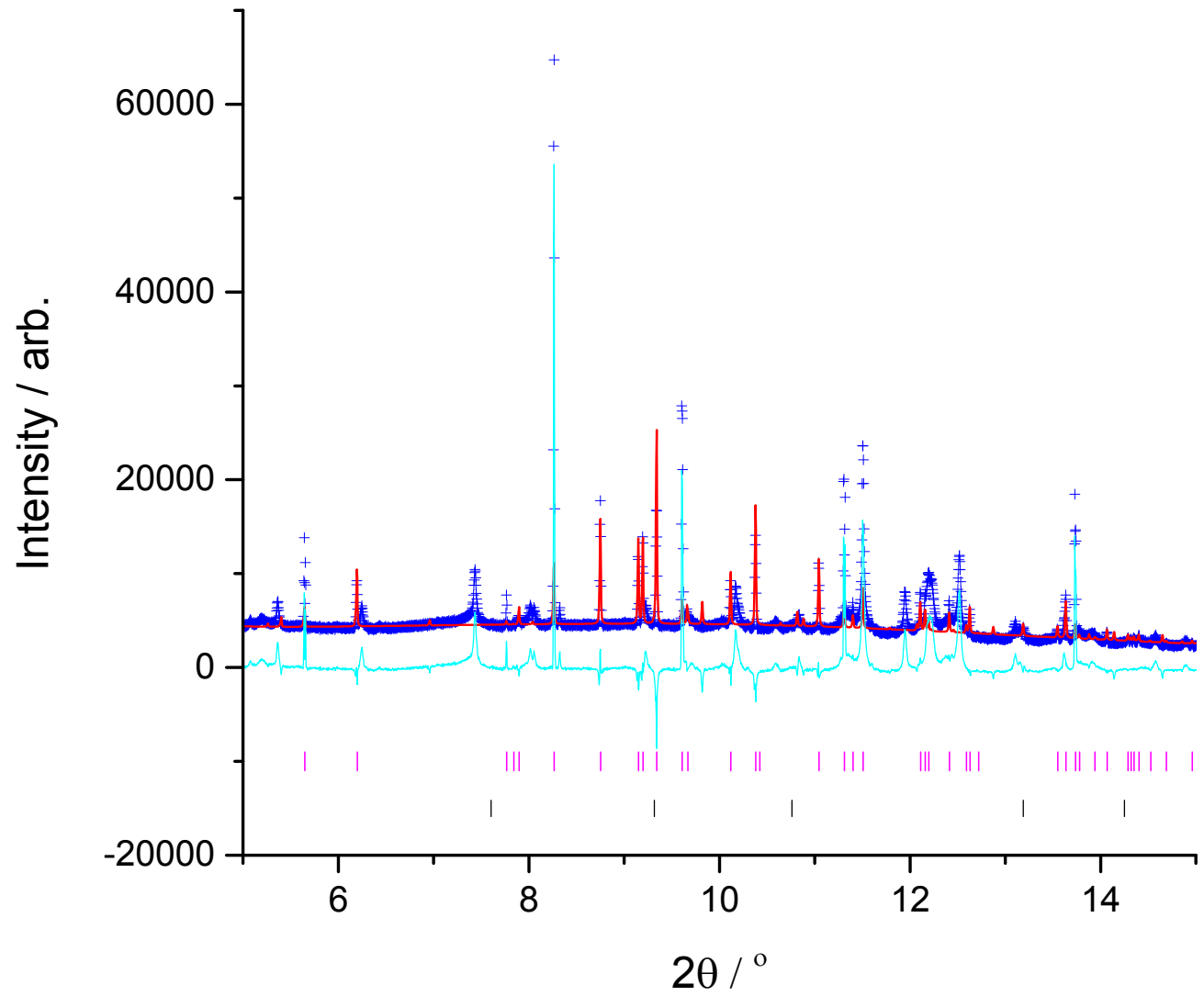

Figure $\mathrm{S} 1.100 \% \mathrm{~K}$ discharged XRD data using $\mathrm{Sc}_{2}\left(\mathrm{MoO}_{4}\right)_{3}$ and $\mathrm{Sc}_{2} \mathrm{O}_{3}$ models, $R_{w p}=23.17 \%$. The data is represented as blue, the calculated model as red line and the difference between the data and the model as the cyan curve below, the magenta points are $\mathrm{Sc}_{2}\left(\mathrm{MoO}_{4}\right)_{3}$ peak markers and the black points are $\mathrm{Sc}_{2} \mathrm{O}_{3}$ peak markers. 
Table S1 Refined crystallographic details for each phase reported in Figure 1.

Pure $\mathrm{Sc}_{2}\left(\mathrm{MoO}_{4}\right)_{3}-\mathrm{Pnca}_{\mathrm{Sc}}\left(\mathrm{MoO}_{4}\right)_{3}$

\begin{tabular}{|c|c|c|c|c|c|}
\hline \multicolumn{6}{|c|}{ Pure $\mathrm{Sc}_{2}\left(\mathrm{MoO}_{4}\right)_{3}-$ Pnca $\mathrm{Sc}_{2}\left(\mathrm{MoO}_{4}\right)_{3}$} \\
\hline Atom & $x$ & $y$ & $z$ & SOF & $\mathrm{U}_{\text {iso }}$ \\
\hline Sc1 & $0.46558(32)$ & $0.38180(24)$ & $0.2491(4)$ & 1 & $0.0233(11)$ \\
\hline Mo2 & 0.25 & 0 & $0.47216(26)$ & 1 & $0.0263(9)$ \\
\hline Mo3 & $0.11713(16)$ & $0.35555(13)$ & $0.39541(18)$ & 1 & $0.0259(7)$ \\
\hline 01 & $0.0907(9)$ & $0.1421(8)$ & $0.0745(10)$ & 1 & $0.029(3)$ \\
\hline $\mathrm{O} 2$ & $0.1303(11)$ & $0.0680(7)$ & $0.3688(12)$ & 1 & $0.042(4)$ \\
\hline $\mathrm{O3}$ & $0.0104(10)$ & $0.2615(7)$ & $0.3182(9)$ & 1 & $0.025(4)$ \\
\hline 04 & $0.3340(9)$ & $0.4151(7)$ & $0.0781(10)$ & 1 & $0.034(4)$ \\
\hline 05 & $0.0722(10)$ & $0.4768(8)$ & $0.3267(11)$ & 1 & $0.045(4)$ \\
\hline 06 & $0.2905(11)$ & $0.3291(7)$ & $0.3595(11)$ & 1 & $0.039(4)$ \\
\hline \multicolumn{6}{|c|}{$12.5 \%$ Li discharged $\mathrm{Sc}_{2}\left(\mathrm{MoO}_{4}\right)_{3}-$ Pnca $\mathrm{Sc}_{2}\left(\mathrm{MoO}_{4}\right)_{3}$} \\
\hline Atom & $x$ & $y$ & $z$ & SOF & $\mathrm{U}_{\text {iso }}$ \\
\hline Sc1 & $0.4663(6)$ & $0.3790(5)$ & $0.2483(7)$ & 1 & $0.0286(22)$ \\
\hline Mo2 & 0.25 & 0 & $0.4736(5)$ & 1 & $0.0345(17)$ \\
\hline Mo3 & $0.1175(3)$ & $0.35581(28)$ & $0.3960(4)$ & 1 & $0.0356(12)$ \\
\hline 01 & $0.0921(18)$ & $0.1407(16)$ & $0.0722(21)$ & 1 & $0.047(7)$ \\
\hline $\mathrm{O} 2$ & $0.1355(20)$ & $0.0603(12)$ & $0.3707(23)$ & 1 & $0.047(7)$ \\
\hline O3 & $0.0243(19)$ & $0.2636(14)$ & $0.3145(17)$ & 1 & $0.027(7)$ \\
\hline 04 & $0.3286(17)$ & $0.4169(12)$ & $0.0821(19)$ & 1 & $0.039(8)$ \\
\hline 05 & $0.0859(17)$ & $0.4728(15)$ & $0.3262(21)$ & 1 & $0.039(8)$ \\
\hline 06 & $0.2966(21)$ & $0.3376(14)$ & $0.3613(20)$ & 1 & $0.046(8)$ \\
\hline \multicolumn{6}{|c|}{$25 \%$ Li discharged $\mathrm{Sc}_{2}\left(\mathrm{MoO}_{4}\right)_{3}-R-3 h \mathrm{Li}_{2} \mathrm{MoO}_{4}$} \\
\hline Atom & $x$ & $y$ & $z$ & SOF & $\mathrm{U}_{\text {iso }}$ \\
\hline Li1 & $0.117(7)$ & $0.434(8)$ & $0.248(12)$ & 1 & $0.003(23)$ \\
\hline Li2 & $0.320(14)$ & $0.816(7)$ & $0.621(10)$ & 1 & $0.04(4)$ \\
\hline Mo1 & $0.1170(7)$ & $0.6454(6)$ & $0.4128(7)$ & 1 & $0.0223(13)$ \\
\hline 01 & $0.0051(20)$ & $0.6587(22)$ & $0.401(4)$ & 1 & $0.011(13)$ \\
\hline $\mathrm{O} 2$ & $0.2350(23)$ & $0.7845(17)$ & $0.419(4)$ & 1 & $0.034(13)$ \\
\hline $\mathrm{O} 3$ & $0.1188(23)$ & $0.5806(16)$ & $0.265(4)$ & 1 & $0.007(11)$ \\
\hline 04 & $0.1198(23)$ & $0.5812(19)$ & $0.560(4)$ & 1 & $0.029(11)$ \\
\hline \multicolumn{6}{|c|}{$25 \%$ Li discharged $\mathrm{Sc}_{2}\left(\mathrm{MoO}_{4}\right)_{3}-$ Pnca $\mathrm{Sc}_{2}\left(\mathrm{MoO}_{4}\right)_{3}$} \\
\hline Atom & $x$ & $y$ & $z$ & SOF & $\mathrm{U}_{\text {iso }}$ \\
\hline Sc1 & $0.1192(29)$ & $0.262(4)$ & $0.490(4)$ & 1 & $0.052(14)$ \\
\hline Mo1 & $0.1369(21)$ & $0.1015(24)$ & $0.1230(24)$ & 1 & $0.029(7)$ \\
\hline Mo2 & 0 & $0.5124(27)$ & 0.25 & 1 & $0.013(8)$ \\
\hline 01 & $-0.067(5)$ & $0.191(8)$ & $0.112(10)$ & 1 & 0.01 \\
\hline $\mathrm{O} 2$ & $0.149(9)$ & $0.026(9)$ & $0.118(11)$ & 1 & 0.01 \\
\hline $\mathrm{O}$ & $0.120(6)$ & $0.280(8)$ & $-0.079(8)$ & 1 & 0.01 \\
\hline 04 & $0.259(4)$ & $-0.024(8)$ & $0.358(10)$ & 1 & 0.01 \\
\hline 05 & $0.166(5)$ & $0.364(8)$ & $0.206(8)$ & 1 & 0.01 \\
\hline 06 & $0.046(5)$ & $0.624(10)$ & $0.101(9)$ & 1 & 0.01 \\
\hline
\end{tabular}




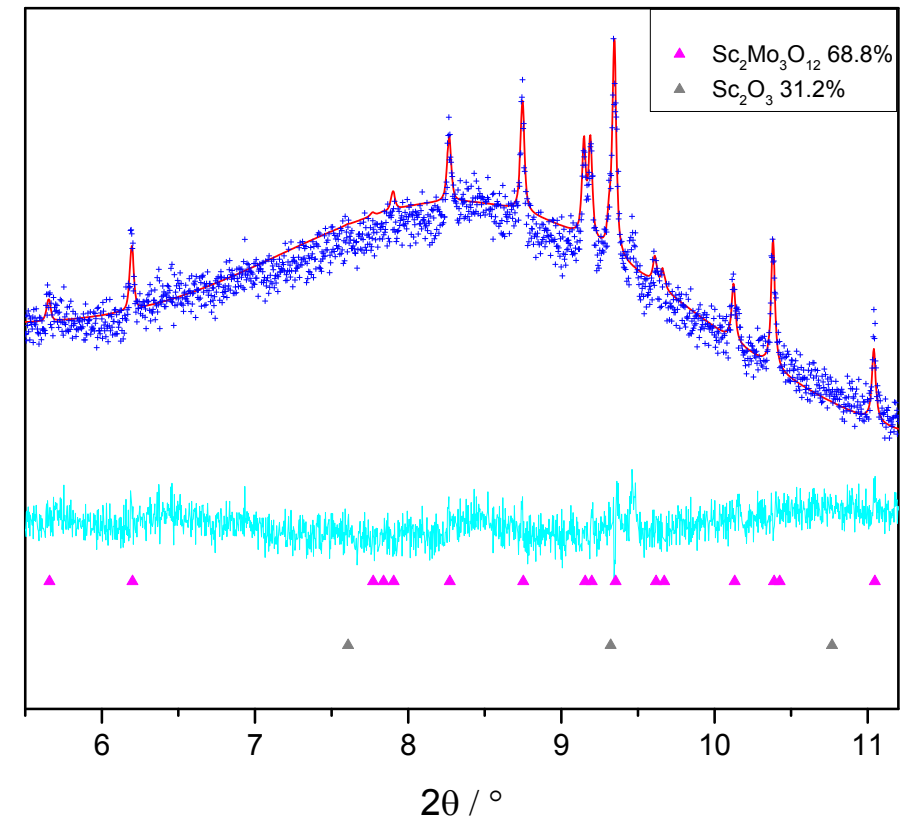

Figure S2 Refinement of room temperature 50\% sodium discharge $\mathrm{Sc}_{2}\left(\mathrm{MoO}_{4}\right)_{3}$. The data is represented as blue, the calculated model as red line and the difference between the data and the model as the cyan curve below, the magenta points are $\mathrm{Sc}_{2}\left(\mathrm{MoO}_{4}\right)_{3}$ peak markers and the grey points are $\mathrm{Sc}_{2} \mathrm{O}_{3}$ peak markers.

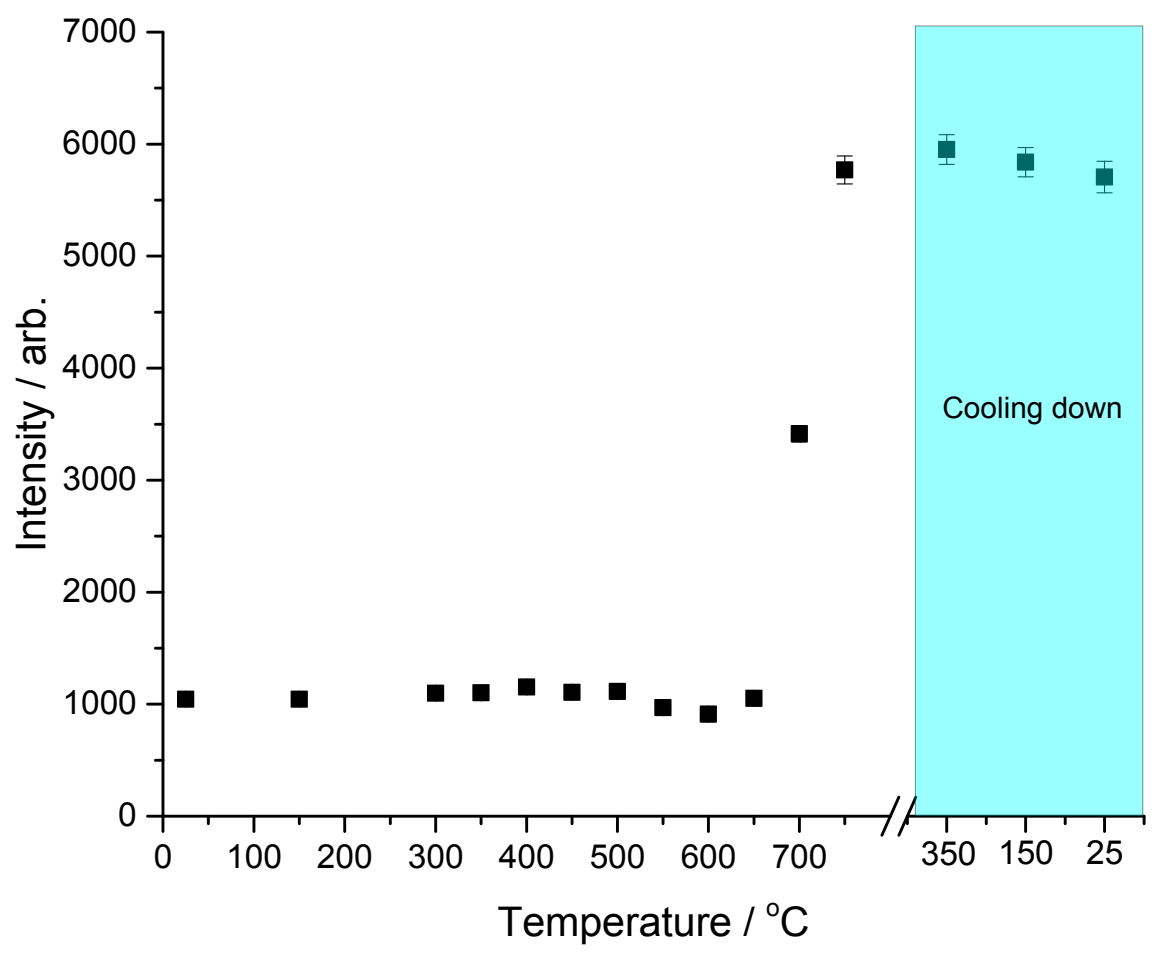

Figure $\mathrm{S} 3$ Single peak fits of the highest intensity reflection of $\mathrm{Sc}_{2} \mathrm{O}_{3}$ in $50 \%$ sodium discharged $\mathrm{Sc}_{2}\left(\mathrm{MoO}_{4}\right)_{3}$ 


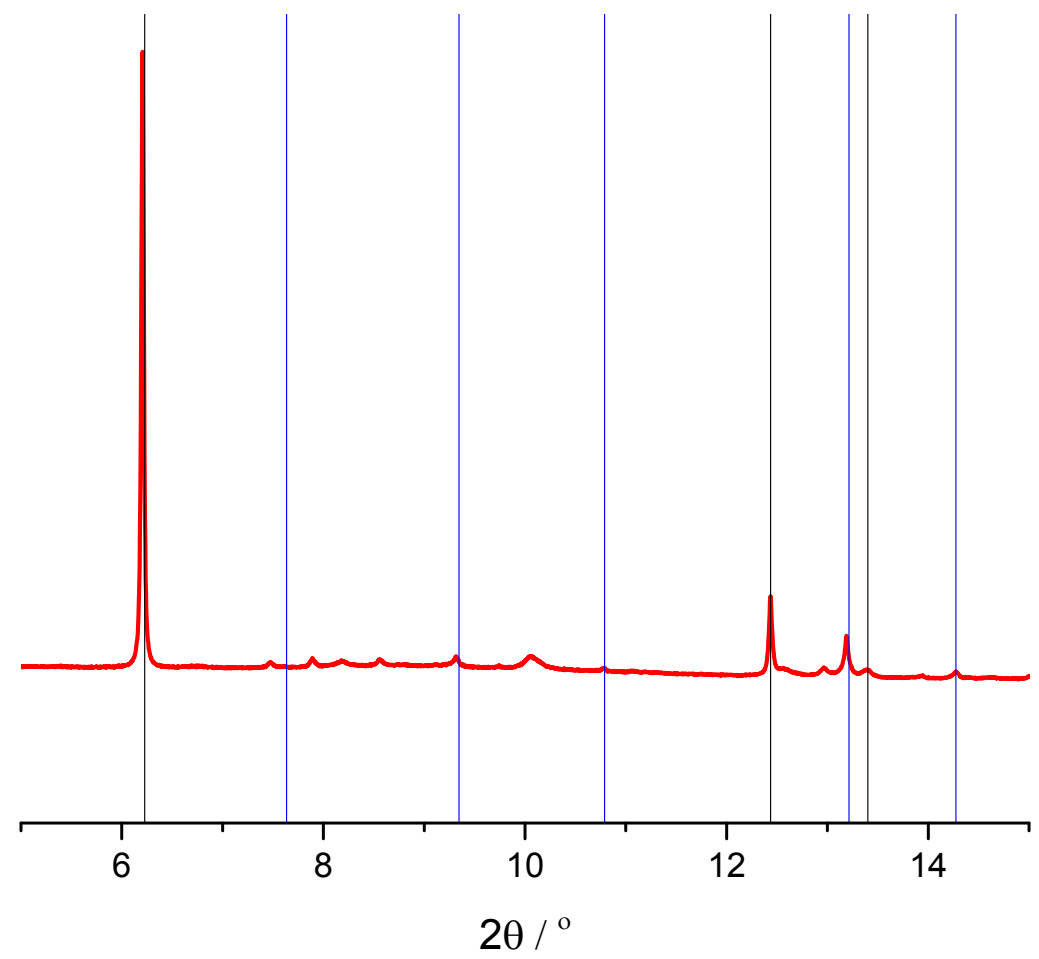

Figure 54 Phase indexing for $50 \%$ Na discharged $\mathrm{Sc}_{2}\left(\mathrm{MoO}_{4}\right)_{3}$ after cooling down, the red line is the data, while the black lines are phase markers for $\mathrm{Na}_{0.9} \mathrm{Mo}_{2} \mathrm{O}_{4}$ and the blue lines are phase markers for $\mathrm{Sc}_{2} \mathrm{O}_{3}$ 


\section{Variable temperature XAS}

Figure S5 and Table S2 shows the oxidation number evolution derived from linear extrapolation from standards as a function of temperature and \% discharge. For $12.5 \%$ lithium discharged $\mathrm{Sc}_{2}\left(\mathrm{MoO}_{4}\right)_{3}$, the oxidation number of molybdenum decreases as temperature increases, and there is a significant change at about $500^{\circ} \mathrm{C}$, from 4.39 to 4.04 , which is close to the decomposition temperature of PVDF (see Figure S2 in ref. 2). At slightly higher temperatures the VT XRD data (Figure S5) indicates a phase change from $\mathrm{Sc}_{2}\left(\mathrm{MoO}_{4}\right)_{3}$ to $\mathrm{Li}_{\mathrm{x}} \mathrm{MoO}_{2}$, which correlates with the oxidation number decrease towards 3 . This illustrates that the heating process results in an overall reduction of Mo, presumably due to the presence of carbon and generation of reductive gases in the sealed quartz capillary.

The $25 \%$ lithium discharged $\mathrm{Sc}_{2}\left(\mathrm{MoO}_{4}\right)_{3}$ has a similar, but lower, oxidation number compared to $12.5 \%$ lithium discharged $\mathrm{Sc}_{2}\left(\mathrm{MoO}_{4}\right)_{3}$ at room temperature. In the case of $25 \%$ lithium discharged, the crystalline component of the electrode is predominantly $\mathrm{Li}_{2} \mathrm{MoO}_{4}$ at room temperature and this component evolves to $\mathrm{Li}_{3} \mathrm{ScMoO}_{3} \mathrm{O}_{12}$ which remains in the same Mo oxidation state. There is no significant oxidation state change with temperature. The $50 \%$ sodium discharged $\mathrm{Sc}_{2}\left(\mathrm{MoO}_{4}\right)_{3}$ has an oxidation number of about 4.6 all the way through from $25{ }^{\circ} \mathrm{C}$ to $750{ }^{\circ} \mathrm{C}$ and on cooling, although $\mathrm{Na}_{0.9} \mathrm{Mo}_{2} \mathrm{O}_{4}$ (expected Mo oxidation state of 3.55) is formed. It should be noted that there are unknown phases in the XRD data which may influence the overall Mo oxidation state. For $100 \%$ potassium discharged $\mathrm{Sc}_{2}\left(\mathrm{MoO}_{4}\right)_{3}$, the oxidation numbers are around 4.5 until $750^{\circ} \mathrm{C}$, during this stage, there is combination of $\mathrm{KMo}_{4} \mathrm{O}_{6}\left(\mathrm{Mo}^{2.75+}\right)$ and $\mathrm{K}_{2} \mathrm{MoO}_{4}\left(\mathrm{Mo}^{6+}\right)$. During cooling it appears that the oxidation number increases in this case, possibly due to the increase in content of $\mathrm{K}_{2} \mathrm{MoO}_{4}$ and decrease of $\mathrm{KMo}_{4} \mathrm{O}_{6}$. Although interesting data, the tendency of Mo to change oxidation state during thermal treatments in a reductive or oxidative manner appears to be \% discharge and phase dependent. This can be rationalised by the reductive environment available from the decomposition of PVDF or the oxidative environment with contact with the quartz capillary.

Table S2 Edge energies used to calculate the oxidation state.

\begin{tabular}{|c|c|c|c|c|c|c|c|c|}
\hline \multirow[b]{2}{*}{$\begin{array}{c}\text { Temperature } \\
\left({ }^{\circ} \mathrm{C}\right)\end{array}$} & \multicolumn{2}{|c|}{$\mathrm{Sc}_{2} \mathrm{Mo}_{3} \mathrm{O}_{12}$ vs $12.5 \% \mathrm{Li}$} & \multicolumn{2}{|c|}{$\mathrm{Sc}_{2} \mathrm{Mo}_{3} \mathrm{O}_{12}$ vs $25 \% \mathrm{Li}$} & \multicolumn{2}{|c|}{$\mathrm{Sc}_{2} \mathrm{Mo}_{3} \mathrm{O}_{12}$ vs $50 \% \mathrm{Na}$} & \multicolumn{2}{|c|}{$\mathrm{Sc}_{2} \mathrm{Mo}_{3} \mathrm{O}_{12}$ vs $100 \% \mathrm{~K}$} \\
\hline & $\begin{array}{c}\text { Edge } \\
\text { Energy } \\
\text { (eV) }\end{array}$ & $\begin{array}{c}\text { Oxidation } \\
\text { Number }\end{array}$ & $\begin{array}{c}\text { Edge } \\
\text { Energy } \\
\text { (eV) }\end{array}$ & $\begin{array}{l}\text { Oxidation } \\
\text { Number }\end{array}$ & $\begin{array}{c}\text { Edge } \\
\text { Energy } \\
(\mathrm{eV})\end{array}$ & $\begin{array}{l}\text { Oxidation } \\
\text { Number }\end{array}$ & $\begin{array}{c}\text { Edge } \\
\text { Energy } \\
\text { (eV) }\end{array}$ & $\begin{array}{c}\text { Oxidation } \\
\text { Number }\end{array}$ \\
\hline 25 & 20004.4 & 4.57 & 20004.3 & 4.45 & 20004.5 & 4.70 & 20004.37 & 4.54 \\
\hline 100 & 20004.52 & 4.72 & 20004.43 & 4.61 & 20004.5 & 4.70 & 20004.38 & 4.55 \\
\hline 200 & 20004.22 & 4.35 & 20004.2 & 4.32 & 20004.3 & 4.45 & 20004.47 & 4.66 \\
\hline 300 & 20004.3 & 4.45 & 20004.34 & 4.50 & 20004.46 & 4.65 & 20004.24 & 4.37 \\
\hline 400 & 20004.1 & 4.20 & 20004.33 & 4.49 & 20004.38 & 4.55 & 20004.52 & 4.72 \\
\hline 425 & 20004.2 & 4.32 & 20004.3 & 4.45 & 20004.42 & 4.60 & 20004.44 & 4.62 \\
\hline 450 & 20004.28 & 4.42 & 20004.22 & 4.35 & 20004.38 & 4.55 & 20004.44 & 4.62 \\
\hline 500 & 20004.25 & 4.39 & 20004.27 & 4.41 & 20004.07 & 4.16 & 20004.4 & 4.57 \\
\hline 600 & 20003.97 & 4.04 & 20004.18 & 4.30 & 20004.28 & 4.42 & 20004.28 & 4.42 \\
\hline 700 & 20003.56 & 3.53 & 20004.22 & 4.35 & 20004.4 & 4.57 & 20004.29 & 4.44 \\
\hline 750 & 20003.3 & 3.20 & N/A & N/A & 20004.41 & 4.59 & 20004.43 & 4.61 \\
\hline cool 350 & N/A & $\mathrm{N} / \mathrm{A}$ & 20004.22 & 4.35 & 20004.3 & 4.45 & 20004.86 & 5.15 \\
\hline cool 150 & N/A & N/A & 20004.4 & 4.57 & 20004.38 & 4.55 & 20004.88 & 5.17 \\
\hline cool 25 & N/A & N/A & 20004.26 & 4.40 & 20004.46 & 4.65 & 20004.73 & 4.98 \\
\hline
\end{tabular}




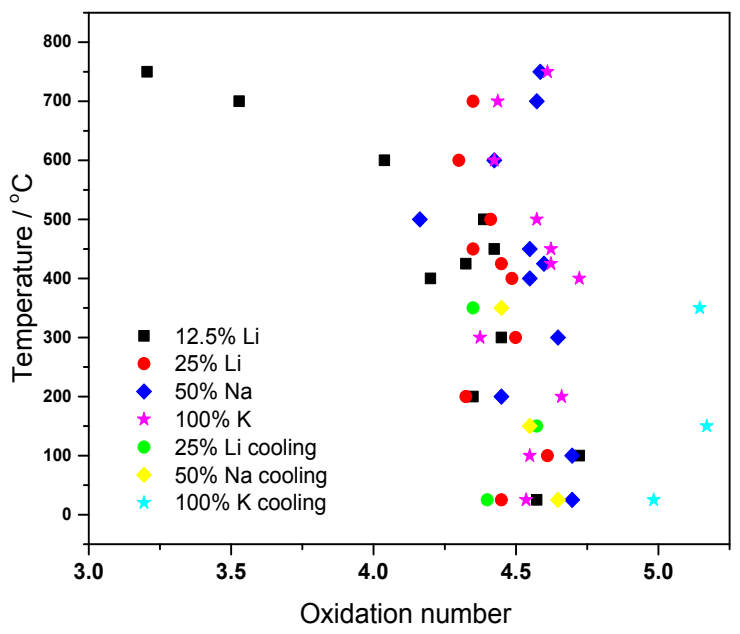

Figure S5 Oxidation numbers calculated as linear interpolation of the energies from the 1st derivative of the XANES spectra at different temperature. 